\title{
Synthesis of Enantiomerically Enriched 1,2,3- Triazole-derivatized Homoalanines
}

\author{
Māris Turks ${ }^{1}$, Nataljja Streḷnikova ${ }^{2}$, Viktors Kumpin̦š $\check{~}^{3}$, Udo Kalējs ${ }^{4}$, \\ ${ }^{1-3}$ Riga Technical University, ${ }^{4}$ Bapeks, Ltd
}

\begin{abstract}
In recent decades, the synthesis of amino acid triazole conjugates has become an emerging area. L- and Dazidohomoalanine derivatives readily undergo copper(I)catalyzed azide-alkyne dipolar cycloaddition reaction. The expected 4-substituted-1H-1,2,3-triazol-1-yl-homoalanines are obtained in the reactions of either $N$ - and $O$-protected or protecting-group-free azidohomoalanines with various alkynes. 1,2,3-Triazole conjugate formation tolerates various functional groups. The synthetic approach that uses $N$ - and $O$-protected starting materials relays on the standard chromatographic purification of intermediates that are further deprotected by hydrogenolysis. In this way, the purification of final products is not required. The synthetic approach that uses protecting-groupfree azidohomoalanine is faster from a synthetic point of view as it includes only one step. However, the purification of protectinggroup-free amino acid derivatives is laborious. Additionally, we have shown that the chiral stationary phase CROWNPAK ${ }^{\circledR}$ CR(+), which is based on chiral crown ether as a selector, is applicable for direct chromatographic determination of enantiomeric ratio of the title products.
\end{abstract}

Keywords: azidohomoalanine, 1,2,3-triazolyl homoalanines, alkynes, azide-alkyne cycloaddition, click chemistry, CROWNPAK ${ }^{\circledR}$ CR(+) stationary phase, enantiomeric purity

\section{INTRODUCTION}

Triazoles belong to the class of privileged molecular motifs that are often used to obtain certain biological activities. Triazole containing compounds are known to possess antibacterial, antihelmintic, antifungal and anticancer properties [1]. When attached to a carbohydrate core, triazole derivatives have found applications as antiviral drugs [2,3] and inhibitors of glycosidases [4,5].

Since 2002, 1,2,3-triazoles are regioselectively assembled in copper-catalyzed azide-alkyne cycloaddition reaction, which was independently discovered by the research groups of Meldal [6] and Sharpless [7].

Also in amino acid chemistry their conjugates with triazoles have found notable applications. Thus, triazolyl amino acid based multidentate chelating systems have been investigated as potential diagnostic and therapeutic tools [8]. Triazoles were used to prepare bis-amino acids that are useful as protein crosslinkers [9]. Variable conjugates of amino acids were made via triazole linkers. Those include triazole tethered ferrocenyl-amino acids [10] and both $C$ - and $N$-glycosyl $\alpha$ amino acids $[11,12]$. On the other hand, both azide- and alkyne-modified amino acids were incorporated into pseudonatural peptides to gain site-specific recombinant infrared probes $[13,14]$. These modified amino acid residues were also used as bioorthogonal chemical reporters [15]. More recently, metal-free strain-promoted azide-alkyne cycloaddition, developed by Bertozzi [16], has evolved as an important biological tool [17]. Also this approach requires the use of azide-modified entities, including amino acids. The aforementioned facts have aroused the interest in the synthesis and transformations of azide-derivatized amino acids [18].

Despite the various applications, including a potential biological activity, only a few series of simple amino acid triazole conjugates have been prepared. These are triazolyl alanines 1 (Fig. 1) that have been studied as selective AMPA receptor ligands [19] and substrates for neutral amino acid transport protein SN1 [20]. Hence, we were intrigued to develop the synthesis of $-\mathrm{CH}_{2}-$ homologs of the reported structures 1: namely 1,2,3-triazolyl homoalanines 2 (Fig. 1).
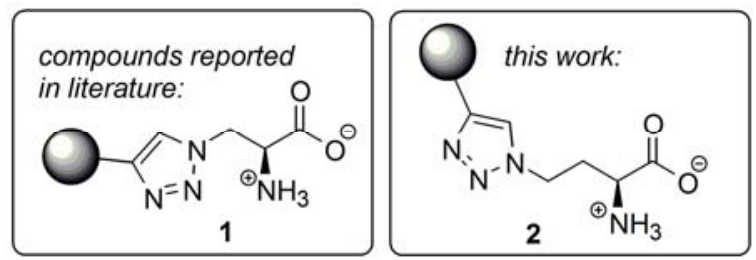

Fig. 1. 1,2,3-Triazolyl alanines 1 versus 1,2,3-triazolyl homoalanines 2

\section{RESULTS AND DISCUSSION}

Here we report the synthesis and enantiomeric purity analysis of 1,2,3-triazolyl-L-homoalanines 2 [21,22]. Both $(S)$ $((S)-3 a)$ and $(R)$-4-azido-2-amino-butyric acid $((R)-3 \mathbf{a})$ or Land D-azidohomoalanine (often abbreviated as Aha) are commercially available in unprotected and variously protected forms, but can be easily prepared from aspartic acid [23] (Fig. 2.).<smiles>N#CC[C@H](N)C(=O)[O-]</smiles>

$(S)-\mathbf{3 a}$ [L-azidohomoalanine]

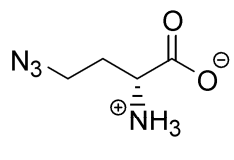

$(R)-3 a$

[D-azidohomoalanine]
Fig. 2. L- and D-Azidohomoalanines

Our synthetic plan included two distinct approaches: 1) the use of fully protected amino acid followed by deprotection as the last step; 2) the use of unprotected amino acid. As unprotected amino acids are usually difficult to purify, we have started our research with fully protected amino acid $(S)$ 3c. The latter was synthesized from $N$-benzyloxycarbonyl-L- 
azidohomoalanine $((S)-3 \mathbf{b})$ and $\mathrm{CbzCl}$ via decarboxylative benzylation procedure in $69 \%$ yield (Scheme 1) [24].

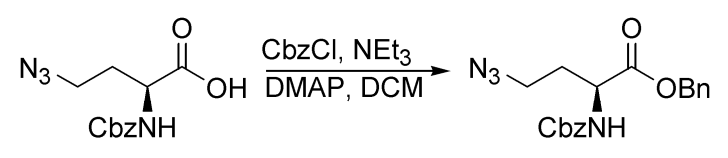

(S)-3b

(S)-3c, $69 \%$

Scheme 1. Synthesis of $N$-benzyloxycarbonyl-L-azidohomoalanine benzyl ester $((S)-\mathbf{3 c})$

With starting material $(S)-\mathbf{3 c}$ in hand, we proceeded to triazole formation. Various reaction conditions for coppercatalyzed azide-alkyne cycloaddition reaction were screened, including the well-established $\mathrm{CuSO}_{4} \cdot 5 \mathrm{H}_{2} \mathrm{O}$ /sodium ascorbate system, $\mathrm{Cu}^{0} / \mathrm{CuSO}_{4}$ and $\mathrm{CuI}$. Various solvent systems (acetone/water, $\mathrm{CH}_{2} \mathrm{Cl}_{2}$ /water, tert-butanol/water, THF) and temperature regimes $\left(20-80{ }^{\circ} \mathrm{C}\right)$ were also explored. A compromise between slow reaction rates and possible racemization at the $\alpha$-carbon of the amino acid had to be found. Thus, $\mathrm{CuSO}_{4} \cdot 5 \mathrm{H}_{2} \mathrm{O} /$ sodium ascorbate catalytic system in acetone/water as a reaction medium was chosen due its mildness regardless of relatively long reaction times (up to 48 hours) (Scheme 2).

A typical experimental procedure for triazole $(S)-\mathbf{4 a - i}$ formation includes mixing of 1 equivalent of azide component $(S)$-3c with 1.5 equivalents of alkyne component $(\mathrm{R}-\equiv)$ in acetone/water mixture followed by sequential addition of aqueous solutions containing $10 \mathrm{~mol} \%$ of copper(II) sulfate and $20 \mathrm{~mol} \%$ of sodium ascorbate. After stirring of the reaction mixture at ambient temperature for $48 \mathrm{~h}$, the products $(S)$-4a-i were isolated by an extractive work-up with $\mathrm{CH}_{2} \mathrm{Cl}_{2}$. The yields of the products $(S)$-4a-i ranged from satisfactory ( $44 \%$ for $\mathbf{4 f}$ ) to excellent ( $84 \%$ for $\mathbf{4 b}$ ) (Scheme 2 , Table 1$)$. It should be mentioned that the lipophilic character of the intermediate products $(S)-\mathbf{4 a - i}$ allows their purifications by classic silica gel column chromatography. On the contrary, the purification of the target products $(S)-\mathbf{2 a - h}$ is feasible only by precipitation/crystallization techniques, ion exchange and reverse phase chromatography. This fact prompted us to choose $\mathrm{N}-\mathrm{Cbz}$ and $\mathrm{O}-\mathrm{Bn}$ protecting groups as the latter are cleanly cleaved under catalytic hydrogenolysis and produce only volatile side products $\left(\mathrm{CO}_{2}\right.$ and toluene). This allows avoiding the extensive purification of the final products, if the intermediates are properly purified. The aforementioned approach is frequently used when the target products are hydrophilic [25]. Thus, hydrogenolysis of $(S)-\mathbf{4 a - i}$ in the presence of catalytic amounts of palladium on activated charcoal ( $10 \%$ palladium content) produced cleanly the expected 4-substituted-1H-1,2,3-triazol-1-yl-L-homoalanines (S)-2a-h (Scheme 2, Table 1). Somewhat lower yields of products are explained by partial adsorption on activated charcoal.
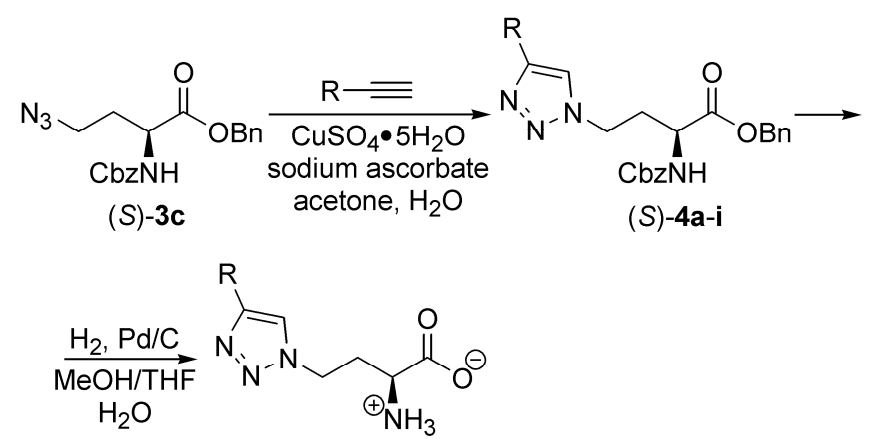

(S)-2a-i

Scheme 2. Synthesis of 1,2,3-triazolyl-L-homoalanines (S)-2a-h via $\mathrm{N}$-Cbz$O$-Bn-protected intermediates $(S)-\mathbf{4 a - i}$

TABLE 1

SYNTHESIS OF PRODUCTS $(S)-\mathbf{2 a - h}$ and $(S)-\mathbf{4 a - i}$ ACCORDING TO SCHEME 2

\begin{tabular}{|c|c|c|c|}
\hline Entry & $\mathrm{R}$ & $\begin{array}{c}\text { Product } \\
(S)-\mathbf{4 a - i}, \\
\text { Yield }\end{array}$ & $\begin{array}{l}\text { Product } \\
(S)-\mathbf{2 a - e} \text { and } \\
(S)-\mathbf{2}, \mathbf{h}, \\
\text { Yield }\end{array}$ \\
\hline 1. & & $4 a, 84 \%$ & 2a, $63 \%$ \\
\hline 2. & ט & $4 b, 56 \%$ & $2 \mathbf{b}, 15 \%$ \\
\hline 3. & & $4 c, 58 \%$ & $2 c, 36 \%$ \\
\hline 4. & & $4 d, 74 \%$ & 2d, $55 \%$ \\
\hline 5. & & $4 e, 65 \%$ & $2 e, 70 \%$ \\
\hline 6. & & $\mathbf{4 f}, 44 \%$ & $-*$ \\
\hline 7. & & $4 \mathrm{~g}, 74 \%$ & $2 \mathrm{~g}, 45 \%$ \\
\hline 8. & & $4 h, 70 \%$ & $2 h, 49 \%$ \\
\hline 9. & & $4 \mathbf{i}, 80 \%$ & _* \\
\hline
\end{tabular}

The latter fact prompted us to explore shortly the possibility of target product synthesis without the use of protecting groups (Scheme 3). Thus, hydrochloride $(S)$-3d was mixed either with 5-hexynnitrile or with 3-butyn-1-ol in the presence of catalytic systems containing $\mathrm{Cu}(\mathrm{I})$. Expected products $(S)$ 2a,c were isolated in $69 \%$ and $60 \%$ yield, respectively. The isolated yields are attributed to highly pure compounds $(>98 \%)$ that were obtained after semi-preparative HPLC 
purification (C18 column Nihon Waters Ltd. $3.9 \times 300$ mm; eluent system water $\rightarrow 10 \% \mathrm{MeOH}$ in water in $8 \mathrm{~min}$ ). Other methods, such as filtration through activated charcoal, manual column chromatography on reverse phase C18 silica gel and ion exchange chromatography, did not provide sufficiently pure material.

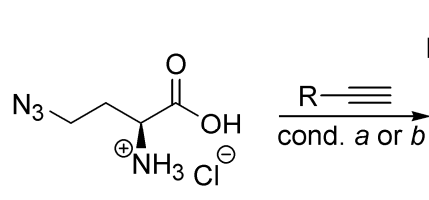

(S)-3d

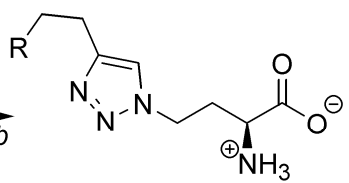

(S)-2a: $\mathrm{R}=-\mathrm{CH}_{2} \mathrm{CN}, 69 \%$ [cond. a]

(S)-2c: $\mathrm{R}=\mathrm{OH}, 60 \%$ [cond. $b$ ]

conditions $b$ :

conditions a:

$\mathrm{CuSO}_{4} \bullet 5 \mathrm{H}_{2} \mathrm{O}$, sodium ascorbate,

acetone $/ \mathrm{H}_{2} \mathrm{O}$, ambient temp.

Scheme 3. Direct synthesis of 4-substituted-1H-1,2,3-triazol-1-yl-Lhomoalanines from L-azidohomoalanine

At this point, one can conclude that the direct synthesis of triazolyl homoalanines (Scheme $3: \mathbf{3 d} \rightarrow \mathbf{2}$ ) is possible and gives comparable or even better yields than a two-step procedure (Scheme $2: \mathbf{3 d} \rightarrow \mathbf{4} \rightarrow \mathbf{2}$ ), but is not very effective due to the laborious purification.

Finally, we turned to the analysis of the enantiomer composition (enantiomeric purity) of the final compounds $(S)$ $\mathbf{2 a - h}$. It is well accepted that the best methods for quantitation of the presence of each of the enantiomers is chromatography on chiral stationary phase [26]. For this reason, the reference sample of $(R)-2$ was required to find the chromatographic conditions. As a representative example, the analysis of $(S)-2 \mathrm{c}$ and $(R)-2 \mathbf{c}$ is described here. A sample of $(R)-2 \mathbf{c}$ was synthesized from $(R)-3 \mathbf{e}$ (Scheme 4). In this case, dicyclohexylammonium salt of $N$-Boc-D-homoalanine $((R)-3 \mathbf{e})$ was used. Copper(I) catalyzed azide-alkyne cycloaddition provided intermediate $(R)-5$ in $80 \%$ yield. The cleavage of $N$ Boc protection in water/trifluoroacetic acid followed by semipreparative HPLC (C18 column Nihon Waters Ltd. $3.9 \times 300$ $\mathrm{mm}$; eluent system water $\rightarrow 10 \% \mathrm{MeOH}$ in water in $8 \mathrm{~min}$ ) provided the target product $(R)-2 \mathrm{c}$ in $49 \%$ yield.

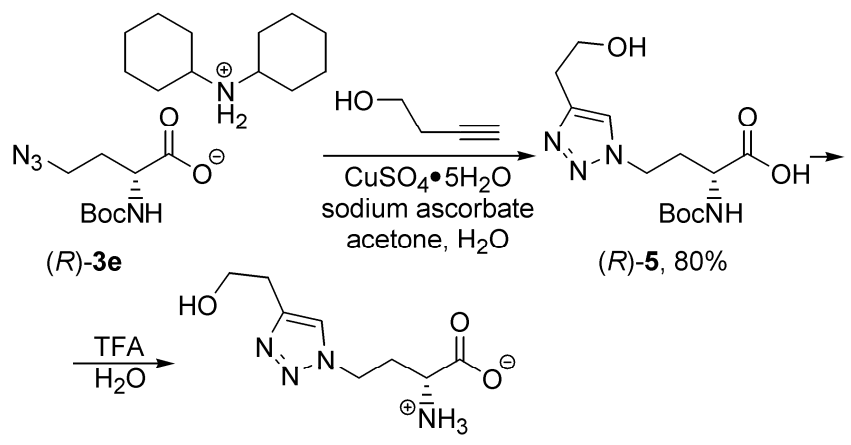

(R)-2c, $49 \%$

Scheme 4. Synthesis of 1,2,3-triazolyl-D-homoalanine $(R)-\mathbf{2 c}$

Mixing of equal amounts of $(R)-2 \mathrm{c}$ and $(S)$-2c gave an "artificial racemate" that was used to develop the chromatographic analysis on chiral stationary phase. The best results were achieved by $\mathrm{CROWNPAK}^{\circledR} \mathrm{CR}(+)$ column, which bears a chiral crown ether as a chiral selector coated onto a $5 \mu \mathrm{m}$ silica support (Fig. 3). It shows that the direct synthesis of $(S)-2 \mathrm{c}$ with $\mathrm{CuI}$ as the catalyst at $+70{ }^{\circ} \mathrm{C}$ results in partial racemization at $\alpha$-carbon: isolated product possesses enantiomeric purity of $95 \%$. However, compound $(R)-\mathbf{2 c}$ obtained at ambient temperature possesses enantiomeric purity greater than $99.5 \%$. Similarly, compounds $(S)$-2a-h (Table 1) revealed excellent enantiomeric purity. In the case of carbohydrate derivative $\mathbf{4 f}$, the diastereomeric purity was additionally proved by ${ }^{1} \mathrm{H}$ - and ${ }^{13} \mathrm{C}-\mathrm{NMR}$ as the spectra revealed only one set of the signals.

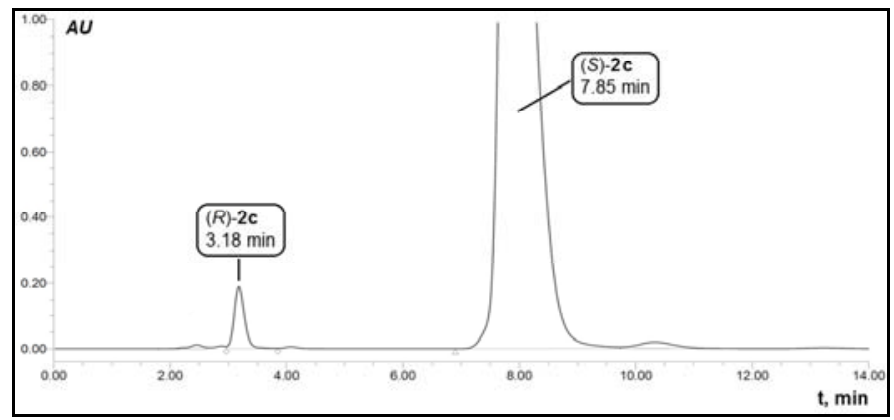

Fig. 3. A chromatogram of $(S)$-2c obtained in the process $(S)$-3d $\rightarrow(S)$-2c representing e.r. 97.5 : $2.5\left(95 \%\right.$ ee). Conditions: CROWNPAK ${ }^{\circledR}$ $\mathrm{CR}(+)$ column $4.6 \times 150 \mathrm{~mm}$; eluent: aqueous $\mathrm{HClO}_{4}, \mathrm{pH} 1$ in isocratic mode; flow: $0.5 \mathrm{ml} / \mathrm{min}$; DAD detector at $220 \mathrm{~nm}$; sample conc.: 4 $\mathrm{mg} / \mathrm{mL}$; injection vol.: $10 \mu \mathrm{L}$.

\section{CONCLUSIONS}

A straightforward way to 4-substituted-1H-1,2,3-triazol-1yl-L-homoalanines is designed starting from Lazidohomoalanine. The synthesis can be accomplished either with or without protecting groups. The synthetic route that includes the use of protecting groups uses well-established laboratory scale purification techniques, such as silica gel column chromatography, and is obviously longer. On the contrary, the direct synthesis of triazolyl homoalanines is possible and at first glance looks simpler. Nevertheless, it requires laborious purification techniques, preferably preparative HPLC. We have shown that chiral homoalanine derivatives are rather resistant towards racemization under given experimental conditions. However, care should be taken when the reactions are performed at elevated temperatures and prolonged reaction times. The developed method is useful for a small scale synthesis of the aforementioned potentially biologically active amino acid derivatives.

\section{EXPERIMENTAL SECTION}

Starting materials $(S)-\mathbf{3 b} \mathbf{b} \mathbf{d}$ and $(R)-\mathbf{3 e}$ were obtained from Bapeks Ltd (Riga, Latvia). Other reagents were obtained from Acros and used without further purification. Yields refer to chromatographically homogeneous compounds. HPLC analysis was performed on Agilent Technologies 1200 series system with DAD detector and Agilent Zorbax SB C18, $4.6 \times$ 
$150 \mathrm{~mm}$ column. Chromatographic conditions $(1 \mathrm{~mL} / \mathrm{min})$ for compounds $(S)-\mathbf{3 c}$ and $(S)-\mathbf{4 a - i}$ : eluent $\mathrm{A}$ : aqueous $0.01 \mathrm{M}$ $\mathrm{KH}_{2} \mathrm{PO}_{4}+6 \% \mathrm{MeOH}$, pH 4.6; eluent $\mathrm{B}: \mathrm{MeOH}$; gradient: $\mathrm{B}$ $0 \% \rightarrow \mathrm{B} 50 \%$ in $10 \mathrm{~min}$. Chromatographic conditions for compound series $(S)$-2a-h: gradient: water $100 \% \rightarrow 50 \%$ $\mathrm{MeOH}$ in water in $10 \mathrm{~min}$. For conditions of chromatography on chiral stationary phase see Fig. 3 in the text of publication. Preparative column chromatography was performed on Rocc silica gel $(40-63 \mu \mathrm{m})$. Merck Silica gel $60 \mathrm{~F}_{254}$ plates were used for TLC analysis of reaction mixtures; visualization was done by UV light or by $1 \%$ ninhydrin in $\mathrm{EtOH}$ followed by heating. Infrared spectra were performed on Perkin-Elmer FTIR system, ${ }^{1} \mathrm{H}$ - and ${ }^{13} \mathrm{C}-\mathrm{NMR}$ analysis were performed on Bruker Ultra Shield apparatus at $300 \mathrm{MHz}$ and $75.5 \mathrm{MHz}$, respectively. The proton signals for residual non-deuterated solvents $\left(\delta 7.26\right.$ for $\mathrm{CDCl}_{3}, 4.79$ for $\mathrm{D}_{2} \mathrm{O}$ and $\delta 2.50$ for $\left.\mathrm{DMSO}_{\mathrm{d} 6}\right)$ and carbon signals $\left(\delta 77.1\right.$ for $\mathrm{CDCl}_{3}$ and $\delta 39.5$ for $\mathrm{DMSO}_{\mathrm{d} 6}$ ) were used as internal references for ${ }^{1} \mathrm{H}-\mathrm{NMR}$ and ${ }^{13} \mathrm{C}-\mathrm{NMR}$ spectra, respectively. Coupling constants are reported in $\mathrm{Hz}$.

General procedure for the synthesis of 1,2,3-triazolyl-Lhomoalanines $(S)-2 a-h$ according to Scheme 2 and Table 1: (S)-2-Amino-4(4-(3-cyanopropyl)-1H-1,2,3-triazol-1-

yl)butyric acid ((S)-2a). Hydrogen atmosphere at ambient pressure was applied to a solution of $(\boldsymbol{S})-\mathbf{4 a}(0.31 \mathrm{~g}, 0.67$ mmol) in a mixture of $\mathrm{MeOH}(5 \mathrm{~mL})$, THF $(2 \mathrm{~mL})$ and water $(0.5 \mathrm{~mL})$ containing $10 \% \mathrm{Pd} / \mathrm{C}(30 \mathrm{mg})$ for 5 hours. The resulting reaction mixture was filtered through a celite pad and washed with $\mathrm{MeOH}(10 \mathrm{~mL})$. The filtrate was evaporated to dryness. The residue was dissolved in water and lyophilized. Product $(S)$-2a $(101 \mathrm{mg}, 63 \%)$ was obtained as amorphous white powder. IR (KBr): 3420, 3125, 3070, 2946, 2602, 1586, 1412, 1349, 1328, 1253, 1216, 1166, 1116, 1075, 1057, 1028. ${ }^{1} \mathrm{H}-\mathrm{NMR}\left(\mathrm{D}_{2} \mathrm{O}, 300 \mathrm{MHz}\right): 7.87$ (s, 1H, H-C (5')), 4.58 (t, 2H, $\left.{ }^{3} J=7.4 \mathrm{~Hz}, \mathrm{H}-\mathrm{C}(4)\right), 3.69\left(\mathrm{t}, 1 \mathrm{H},{ }^{3} J=6.6 \mathrm{~Hz}, \mathrm{H}-\mathrm{C}(2)\right), 2.85$ (t, $\left.2 \mathrm{H},{ }^{3} \mathrm{~J}=7.2 \mathrm{~Hz} \mathrm{H}-\mathrm{C}\left(1^{\prime \prime}\right)\right), 2.46$ (m, 4H, H-C(3); H-C(3', )), 2.00 (quint, $\left.2 \mathrm{H},{ }^{3} \mathrm{~J}=7.2 \mathrm{~Hz} \mathrm{H}-\mathrm{C}\left(2{ }^{\prime \prime}\right)\right)$ ). ${ }^{13} \mathrm{C}-\mathrm{NMR}\left(\mathrm{D}_{2} \mathrm{O}, 75.5\right.$ MHz): 171.1, 144.2, 121.7, 119.1, 49.9, 44.3, 28.8, 22.0, 21.3, 13.4. Elem. Anal.: Calcd for $\mathrm{C}_{10} \mathrm{H}_{16} \mathrm{~N}_{5} \mathrm{O}_{2}(237.26) \mathrm{C} 50.62, \mathrm{H}$ 6.37, N 29.52; Found C 50.31, H 6.55, N 29.27.

(S)-2-Amino-4(4-(3-hydroxypropyl)-1H-1,2,3-triazol-1yl)butyric acid ((S)-2b). IR (KBr): 3337, 3138, 2945, 2874, 2604, 1586, 1433, 1412, 1390, 1350, 1329, 1254, 1219, 1165 , $1148,1116,1065,1052,1031,1010 .{ }^{1} \mathrm{H}-\mathrm{NMR}\left(\mathrm{DMSO}_{\mathrm{d} 6}, 300\right.$ $\mathrm{MHz}): 7.85$ (s, 1H, H-C(5')), 4.59 (t, $2 \mathrm{H},{ }^{3} J=7.4 \mathrm{~Hz}, \mathrm{H}-$ $\mathrm{C}(4)), 3.72\left(\mathrm{t}, 1 \mathrm{H},{ }^{3} J=6.6 \mathrm{~Hz}, \mathrm{H}-\mathrm{C}(2)\right), 3.63$ (t, $2 \mathrm{H},{ }^{3} J=6.3$ $\mathrm{Hz} \mathrm{H}-\mathrm{C}\left(3^{\prime}\right.$ ')), 2.78 (t, 2H, $\left.{ }^{3} \mathrm{~J}=7.4 \mathrm{~Hz} \mathrm{H}-\mathrm{C}\left(1^{\prime}{ }^{\prime}\right)\right), 2.73$ (s, 1H, $\mathrm{OH}), 2.47$ (m, 2H, H- C(3)), 1.91 (quint, $2 \mathrm{H},{ }^{3} \mathrm{~J}=7.0 \mathrm{~Hz}, \mathrm{H}-$ $\mathrm{C}(2, ')) .{ }^{13} \mathrm{C}-\mathrm{NMR}\left(\mathrm{DMSO}_{\mathrm{d} 6}, 75.5 \mathrm{MHz}\right): 173.0,147.6,123.3$, 60.9, 52.0, 46.4, 31.0, 30.9, 20.9.

(S)-2-Amino-4(4-(2-hydroxyethyl)-1H-1,2,3-triazol-1yl)butyric acid ((S)-2c). IR (KBr): 3133, 2932, 2600, 2091, 1598, 1462, 1411, 1391, 1350, 1329, 1254, 1219, 1073, 1052, 1025. ${ }^{1} \mathrm{H}-\mathrm{NMR}\left(\mathrm{D}_{2} \mathrm{O}, 300 \mathrm{MHz}\right): 7.89$ (s, 1H, H-C (5')), 4.61 $\left(\mathrm{t}, 2 \mathrm{H},{ }^{3} \mathrm{~J}=7.4 \mathrm{~Hz}, \mathrm{H}-\mathrm{C}(4)\right), 3.87\left(\mathrm{t}, 2 \mathrm{H},{ }^{3} \mathrm{~J}=6.3 \mathrm{~Hz}, \mathrm{H}-\right.$ $\left.\mathrm{C}\left(2^{\prime \prime}\right)\right), 3.73\left(\mathrm{t}, 1 \mathrm{H},{ }^{3} \mathrm{~J}=6.6 \mathrm{~Hz} \mathrm{H}-\mathrm{C}(2)\right), 2.96$ (t, $2 \mathrm{H},{ }^{3} \mathrm{~J}=6.3$ $\left.\mathrm{Hz}, \mathrm{H}-\mathrm{C}\left(1{ }^{\prime \prime}\right)\right), 2.47$ (m, 2H, H-C(3)). ${ }^{13} \mathrm{C}-\mathrm{NMR}\left(\mathrm{D}_{2} \mathrm{O}, 75.5\right.$
MHz): 173.2, 145.2, 124.0, 60.5, 52.0, 46.5, 34.0, 27.7. HRMS (ESI-TOF): Calcd $\left[\mathrm{C}_{8} \mathrm{H}_{14} \mathrm{~N}_{4} \mathrm{O}_{3}+\mathrm{H}\right]^{+}$215.1144; Found 215.1168

(S)-2-Amino-4(4-phenyl-1H-1,2,3-triazol-1-yl)butyric acid ((S)-2d). IR (KBr): 3424, 3087, 2926, 1587, 1412, 1385, $1348,1335,1145,1114,1082 .{ }^{1} \mathrm{H}-\mathrm{NMR}\left(\mathrm{DMSO}_{\mathrm{d} 6}, 300 \mathrm{MHz}\right)$ : 8.40 (s, 1H, H-C(5')), $7.86\left(\mathrm{dd}, 2 \mathrm{H},{ }^{3} J=7.0 \mathrm{~Hz},{ }^{4} J=1.2 \mathrm{~Hz}\right.$, $\mathrm{H}-\mathrm{C}(\mathrm{Ph})), 7.57\left(\mathrm{dd}, 2 \mathrm{H},{ }^{3} J=7.0 \mathrm{~Hz},{ }^{4} J=1.2 \mathrm{~Hz}, \mathrm{H}-\mathrm{C}(\mathrm{Ph})\right)$, 4.49 (m, 1H, H-C(Ph)), 4.69 (t, 2H, $\left.{ }^{3} J=7.8 \mathrm{~Hz}, \mathrm{H}-\mathrm{C}(4)\right), 3.73$ (t, $\left.1 \mathrm{H},{ }^{3} \mathrm{~J}=6.6 \mathrm{~Hz}, \mathrm{H}-\mathrm{C}(2)\right), 2.51$ (m, 2H, H-C(3)).

(S)-2-Amino-4(4-(4-methylphenyl)-1H-1,2,3-triazol-1yl)butyric acid ((S)-2e). IR (KBr): 3409, 2924, 1581, 1456, 1385, 1150. ${ }^{1} \mathrm{H}-\mathrm{NMR}\left(\mathrm{DMSO}_{\mathrm{d} 6}, 300 \mathrm{MHz}\right): 8.35$ (s, 1H, H$\left.\mathrm{C}\left(5^{\prime}\right)\right), 7.75$ (d, 2H, $\left.{ }^{3} J=7.8 \mathrm{~Hz}, \mathrm{H}-\mathrm{C}(\mathrm{Ph})\right), 7.39$ (d, 2H, ${ }^{3} \mathrm{~J}=$ $7.4 \mathrm{~Hz}, \mathrm{H}-\mathrm{C}(\mathrm{Ph})), 4.69$ (m, 2H, H-C(4)), 3.61 (t, 1H, ${ }^{3} J=6.3$ Hz, H-C(2)), 2.51 (m, 2H, H-C(3)), 2.40 (s, 3H, Ph- $\underline{\mathrm{CH}}_{3}$ ).

(S)-2-Amino-4(4-(1-hydroxycyclohexyl)-1H-1,2,3-triazol1-yl)butyric acid ((S)-2g). IR (KBr): 3257, 3135, 2931, 2858, 1631, 1557, 1454, 1440, 1404, 1352, 1333, 1184, 1168, 1130, 1078, 1058. ${ }^{1} \mathrm{H}-\mathrm{NMR}\left(\mathrm{DMSO}_{\mathrm{d} 6}, 300 \mathrm{MHz}\right): 8.00$ (s, 1H, H$\left.\mathrm{C}\left(5^{\prime}\right)\right), 4.62$ (t, $\left.2 \mathrm{H},{ }^{3} J=7.4 \mathrm{~Hz}, \mathrm{H}-\mathrm{C}(4)\right), 3.73$ (t, $1 \mathrm{H},{ }^{3} J=6.6$ $\mathrm{Hz}, \mathrm{H}-\mathrm{C}(2)), 2.48$ (m, 2H, H-C(3)), 2.10 (m, 2H, H-C(Cy)), 1.84 (m, 2H, H-C(Cy)), 1.69 (m, 2H, H- C(Cy)), 1.52 (m, 2H, H- C(Cy)), 1.44 (m, 2H, H-C(Cy)). ${ }^{13} \mathrm{C}-\mathrm{NMR}\left(\mathrm{DMSO}_{\mathrm{d} 6}, 75.5\right.$ $\mathrm{MHz})$ : 173.0, 145.2, 122.8, 69.7, 52.0, 46.6, 36.9, 36.8, 31.0 (2C), 24.7, 21.8. HRMS (ESI-TOF): Calcd $\left[\mathrm{C}_{12} \mathrm{H}_{20} \mathrm{~N}_{4} \mathrm{O}_{3}+\mathrm{H}\right]^{+}$ 269.1614; Found 269.1640.

(S)-2-Amino-4(4-(2-hydroxypropan-2-yl)-1H-1,2,3triazol-1-yl)butyric acid ((S)-2h). IR (KBr): 3272, 3123, 3076, 2985, 2761, 2599, 1609, 1557, 1539, 1472, 1442, 1417, 1385, 1369, 1353, 1323, 1303, 1221, 1161, 1144, 1050, 956. ${ }^{1} \mathrm{H}-\mathrm{NMR}\left(\mathrm{DMSO}_{\mathrm{d} 6}, 300 \mathrm{MHz}\right): 7.98\left(\mathrm{~s}, 1 \mathrm{H}, \mathrm{H}-\mathrm{C}\left(5^{\prime}\right)\right), 4.62(\mathrm{t}$, $\left.2 \mathrm{H},{ }^{3} \mathrm{~J}=7.0 \mathrm{~Hz}, \mathrm{H}-\mathrm{C}(4)\right), 3.79(\mathrm{~s}, 1 \mathrm{H}, \mathrm{OH}), 3.73\left(\mathrm{t}, 1 \mathrm{H},{ }^{3} \mathrm{~J}=\right.$ $6.6 \mathrm{~Hz}, \mathrm{H}-\mathrm{C}(2)), 2.47$ (m, 2H, H-C(3)), $1.62\left(\mathrm{~s}, 6 \mathrm{H}, \mathrm{CH}_{3}\right) .{ }^{13} \mathrm{C}-$ NMR (DMSO $\left.{ }_{\mathrm{d} 6}, 75.5 \mathrm{MHz}\right): 173.2,154.8,121.9,68.1,52.0$, 46.5, 30.9, 28.8. HRMS (ESI-TOF): Calcd $\left[\mathrm{C}_{9} \mathrm{H}_{16} \mathrm{~N}_{4} \mathrm{O}_{3}+\mathrm{H}\right]^{+}$ 229.1301; Found 229.1311.

Synthesis of (S)-2-Amino-4(4-(3-cyanopropyl)-1H-1,2,3triazol-1-yl)butyric acid ((S)-2a) according to Scheme 3: 5Hexynnitrile $(87 \mu \mathrm{L}, 0.83 \mathrm{mmol})$ was added to a solution of $(S)-3 d$ (100 mg, $0.55 \mathrm{mmol})$ in acetone $(2 \mathrm{~mL})$ at ambient temperature followed by addition of a solution of $\mathrm{CuSO}_{4} \cdot 5 \mathrm{H}_{2} \mathrm{O}(14 \mathrm{mg}, 0.06 \mathrm{mmol})$ in water $(1 \mathrm{~mL})$ and a solution of sodium ascorbate $(22 \mathrm{mg}, 0.11 \mathrm{mmol})$ in water $(1$ $\mathrm{mL}$ ). The resulting reaction mixture was stirred at ambient temperature for 48 hours. Then it was evaporated to dryness and redissolved in $10 \%$ aqueous trifluoroacetic acid $(2 \mathrm{~mL})$. The latter solution was passed through a pad of $\mathrm{C} 18$ reversed phase silica gel and further eluted with water $(25 \mathrm{~mL})$ and methanol $(30 \mathrm{~mL})$. The product-containing fractions were evaporated and additionally purified by semi-preparative HPLC purification (C18 column Nihon Waters Ltd. $3.9 \times 300$ $\mathrm{mm}$; eluent system water $\rightarrow 10 \% \mathrm{MeOH}$ in water in $8 \mathrm{~min}$ ). After lyophilisation (S)-2a (91 mg, 69\%) was obtained as white amorphous powder.

Synthesis of (S)-2-Amino-4(4-(2-hydroxyethyl)-1H-1,2,3triazol-1-yl)butyric acid $((S)-2 c)$ according to Scheme 3: 
$\mathrm{CuI}(20 \mathrm{mg}, 0.11 \mathrm{~mol})$ and DIPEA $(38 \mu \mathrm{L}, 0.22 \mathrm{mmol})$ were added to a stirred solution of $(S)-3 d(190 \mathrm{mg}, 1.05 \mathrm{mmol})$ and 3-butyn-1-ol (123 $\mu \mathrm{L}, 1.62 \mathrm{mmol})$ in a mixture of water (3 $\mathrm{mL})$ and THF $(1 \mathrm{~mL})$. The resulting reaction mixture was heated at $70{ }^{\circ} \mathrm{C}$ for 5 hours. The reaction mixture was evaporated to dryness, redissolved in water $(3 \mathrm{~mL})$ and the resulting solution was passed through a pad of activated charcoal. The charcoal pad was further eluted with water (50 $\mathrm{mL})$ and methanol $(50 \mathrm{~mL})$. The product-containing fractions were evaporated and additionally purified by semi-preparative HPLC purification (C18 column Nihon Waters Ltd. $3.9 \times 300$ $\mathrm{mm}$; eluent system water $\rightarrow 10 \% \mathrm{MeOH}$ in water in $8 \mathrm{~min}$ ). After lyophilisation (S)-2c (136 mg, 60\%) was obtained as white amorphous powder.

Synthesis of $(R)-2-A m i n o-4(4-(2-h y d r o x y e t h y l)-1 H-1,2,3-$ triazol-1-yl)butyric acid $((R)-2 c)$ according to Scheme 4: 3butyn-1-ol (31 $\mu \mathrm{L}, 0.43 \mathrm{mmol})$ was added to a solution of $(R)$ 3e $(102 \mathrm{mg}, 0.24 \mathrm{mmol})$ in acetone $(2 \mathrm{~mL})$ at ambient temperature followed by addition of a solution of $\mathrm{CuSO}_{4} \cdot 5 \mathrm{H}_{2} \mathrm{O}(8 \mathrm{mg}, 0.03 \mathrm{mmol})$ in water $(1 \mathrm{~mL})$ and a solution of sodium ascorbate $(12 \mathrm{mg}, 0.06 \mathrm{mmol})$ in water (1 $\mathrm{mL})$. The resulting reaction mixture was stirred at ambient temperature for 20 hours. Then it was evaporated to dryness and redissolved in $1 \mathrm{M}$ aqueous $\mathrm{Na}_{2} \mathrm{SO}_{4}$ solution $(10 \mathrm{~mL})$ acidified with $\mathrm{NaHSO}_{4}$ to $\mathrm{pH} 2.5$. The aqueous phase was extracted with DCM $(6 \times 7 \mathrm{~mL})$. The combined organic layer was dried $\left(\mathrm{Na}_{2} \mathrm{SO}_{4}\right)$, filtered and evaporated. Silica gel column chromatography provided $(R)-5(60 \mathrm{mg}, 80 \%)$ as yellowish oil. The latter was emulsified in a mixture consisting of water $(1 \mathrm{~mL})$ and trifluoroacetic acid $(100 \mu \mathrm{L})$ and stirred for 2 hours at ambient temperature. Then the reaction mixture was evaporated to dryness. Water $(2 \mathrm{~mL})$ was added and the evaporation was repeated until no trifluoroacetic acid could be detected. The product was purified by semi-preparative HPLC purification (C18 column Nihon Waters Ltd. $3.9 \times 300 \mathrm{~mm}$; eluent system water $\rightarrow 10 \% \mathrm{MeOH}$ in water in $8 \mathrm{~min})$. After lyophilisation (R)-2c (20 mg, 49\% [40\% after 2 steps]) was obtained as white amorphous powder.

(S)-Benzyl 4-azido-2-(benzyloxycarbonylamino)butanoate ((S)-3c). $\mathrm{CbzCl}(1.28 \mathrm{~mL}, 8.98 \mathrm{mmol})$ was slowly added to an ice-cold solution of $(S)$-3b (2.50 g, 8.98 $\mathrm{mmol})$ and $\mathrm{NEt}_{3}(1.38 \mathrm{~mL}, 9.88 \mathrm{mmol})$ in DCM $(50 \mathrm{~mL})$. After 5 minutes DMAP $(0.11 \mathrm{~g}, 0.90 \mathrm{mmol})$ was added at $0{ }^{\circ} \mathrm{C}$ and the resulting mixture was stirred at ambient temperature for 17 hours. Then it was transferred into a separatory funnel and washed with saturated aqueous solution of $\mathrm{NaHCO}_{3}(3 \times 15$ $\mathrm{mL})$. Organic phase was additionally washed with $2 \%$ aqueous $\mathrm{HCl}(3 \times 15 \mathrm{~mL})$ and brine $(20 \mathrm{~mL})$, dried $\left(\mathrm{Na}_{2} \mathrm{SO}_{4}\right)$, filtered and evaporated under reduced pressure. The residue was purified by silica gel column chromatography $(10 \%$ hexanes in toluene). Product $(S)-3 \mathrm{c}(2.30 \mathrm{~g}, 69 \%)$ was obtained as colourless oil; HPLC purity $98 \%\left(\mathrm{t}_{R}=3.23 \mathrm{~min}\right)$.

General procedure for the synthesis of 1,2,3-triazolyl-lhomoalanines (S)-4a-i according to Scheme 2 and Table 1: (S)-Benzyl 2-(benzyloxycarbonylamino)-4-(4-(3cyanopropyl)-1H-1,2,3-triazol-1-yl)butanoate ((S)-4a). 5Hexynnitrile $(214 \mu \mathrm{L}, 2.04 \mathrm{mmol})$ was added to a solution of
$(S)-3 \mathrm{c}(501 \mathrm{mg}, 1.36 \mathrm{mmol})$ in acetone $(6 \mathrm{~mL})$ at ambient temperature followed by addition of a solution of $\mathrm{CuSO}_{4} \cdot 5 \mathrm{H}_{2} \mathrm{O}(35 \mathrm{mg}, 0.14 \mathrm{mmol})$ in water $(1 \mathrm{~mL})$ and a solution of sodium ascorbate $(55 \mathrm{mg}, 0.28 \mathrm{mmol})$ in water (1 $\mathrm{mL})$. The resulting reaction mixture was stirred at ambient temperature for 48 hours and the acetone was evaporated under reduced pressure. The residue was diluted with DCM $(15 \mathrm{~mL})$ and the resulting biphasic mixture was transferred to a separatory funnel. The layers were separated and the aqueous layer was extracted with DCM $(5 \mathrm{~mL})$. The combined organic layer was washed with brine $(2 \times 10 \mathrm{~mL})$, dried $\left(\mathrm{Na}_{2} \mathrm{SO}_{4}\right)$, filtered and evaporated. Silica gel column chromatography provided (S)-4a (527 mg, 84\%) as yellowish oil. IR (KBr): 3335, 3141, 3035, 2954, 1722, 1530, 1499, 1455, 1381, 1382, 1268, 1216, 1054. ${ }^{1} \mathrm{H}-\mathrm{NMR}\left(\mathrm{CDCl}_{3}, 300\right.$ $\mathrm{MHz}): 7.35$ (m, 11H, H-C(Ph), H-C (5')), 5.65 (d, $1 \mathrm{H},{ }^{3} J=8.1$ $\mathrm{Hz}, \mathrm{NH}), 5.12,5.11\left(2 \mathrm{~s}, 4 \mathrm{H}, \mathrm{O}-\mathrm{CH}_{2}-\mathrm{Ph}\right), 4.38$ (m, 3H, H-C(4, 2)), $2.82\left(\mathrm{t}, 2 \mathrm{H},{ }^{3} \mathrm{~J}=7.2 \mathrm{~Hz}, \mathrm{H}-\mathrm{C}\left(1^{\prime}\right)\right.$ '), $2.50-2.27$ (m, 2H, H$\mathrm{C}(3)), 2.38\left(\mathrm{t}, 2 \mathrm{H},{ }^{3} \mathrm{~J}=7.4 \mathrm{~Hz}, \mathrm{H}-\mathrm{C}\left(3{ }^{\prime}\right.\right.$ ') ), 2.03 (quin, $2 \mathrm{H},{ }^{3} \mathrm{~J}=$ 7.2 Hz H-C(2'")). ${ }^{13} \mathrm{C}-\mathrm{NMR}\left(\mathrm{CDCl}_{3}, 75.5 \mathrm{MHz}\right)$ : 170.4, 155.6, 144.9, 135.4, 134.3 128.1, 128.0, 127.9, 127.7, 127.7, 127.5, 121.5, 118.9, 67.0, 66.6, 51.0, 45.8, 32.2, 24.2, 23.5, 15.7.

(S)-Benzyl 2-(benzyloxycarbonylamino)-4-(4-(3hydroxypropyl)-1H-1,2,3-triazol-1-yl)butanoate ((S)-4b). IR (KBr): 3339, 3143, 3065, 3035, 2948, 1722, 1534, 1499, 1455, 1382, 1337, 1268, 1216, 1056. ${ }^{1} \mathrm{H}-\mathrm{NMR}\left(\mathrm{CDCl}_{3}, 300\right.$ $\mathrm{MHz}): 7.30$ (m, 11H, H-C(Ph), H-C(5')), 6.06 (d, $1 \mathrm{H},{ }^{3} \mathrm{~J}=8.1$ $\mathrm{Hz}, \mathrm{HN}), 5.09 ; 5.08$ (2s, 4H, O- $\left.\mathrm{CH}_{2}-\mathrm{Ph}\right), 4.34$ (m, 3H, H-C(2), $\mathrm{H}-\mathrm{C}(4)), 3.63$ (t, $\left.2 \mathrm{H},{ }^{3} \mathrm{~J}=6.2 \mathrm{~Hz}, \mathrm{H}-\mathrm{C}\left(3^{\prime}{ }^{\prime}\right)\right), 3.31$ (bs, $1 \mathrm{H}$, $\mathrm{OH}), 2.75$ (t, 2H, $\left.{ }^{3} \mathrm{~J}=7.4 \mathrm{~Hz}, \mathrm{H}-\mathrm{C}\left(1^{\prime},\right)\right), 2.45-2.26$ (m, 2H, H$\mathrm{C}(3)$ ), 1.86 (quin, $2 \mathrm{H},{ }^{3} \mathrm{~J}=6.9 \mathrm{~Hz}, \mathrm{H}-\mathrm{C}\left(2{ }^{\prime}\right.$ ')). ${ }^{13} \mathrm{C}-\mathrm{NMR}$ $\left(\mathrm{CDCl}_{3}, 75.5 \mathrm{MHz}\right)$ : 171.0, 156.1, 147.3, 135.8, 134.7, 128.5, $128.4,128.3,128.1,128.0,127.8,121.6,67.3,67.0,61.2$, 51.5, 46.1, 32.5, 31.7, 21.7.

(S)-Benzyl 2-(benzyloxycarbonylamino)-4-(4-(2hydroxyethyl)-1H-1,2,3-triazol-1-yl)butanoate ((S)-4c). IR (KBr): 3308, 3145, 3065, 3035, 2953, 1721, 1535, 1499, 1455, 1381, 1336, 1268, 1216, 1054. ${ }^{1} \mathrm{H}-\mathrm{NMR}\left(\mathrm{CDCl}_{3}, 300 \mathrm{MHz}\right)$ : 7.41 (bs, 1H, H-C(5')), 7.33 (m, 10H, H-C(Ph)), 5.74 (d, 1H, $\left.{ }^{3} J=7.9 \mathrm{~Hz}, \mathrm{NH}\right), 5.10,5.09$ (2s, 4H, O- $\left.\mathrm{CH}_{2}-\mathrm{Ph}\right), 4.36$ (m, 3H, $\mathrm{H}-\mathrm{C}(2), \mathrm{H}-\mathrm{C}(4)), 3.89$ (bs, 1H, OH), 2.89 (m, 2H, H-C(1', )), $2.73\left(\mathrm{~m}, 2 \mathrm{H}, \mathrm{H}-\mathrm{C}\left(2{ }^{\prime}\right)\right), 2.49-2.28(2 \mathrm{~m}, 2 \mathrm{H}, \mathrm{H}-\mathrm{C}(3)) .{ }^{13} \mathrm{C}-$ NMR $\left(\mathrm{CDCl}_{3}, 75.5 \mathrm{MHz}\right): 171.4,156.5,148.5,136.2,135.1$, $134.1,128.9,128.8,128.7,128.6,128.5,128.3,67.8,67.4$, $61.7,51.8,46.7,31.0,29.0$.

(S)-Benzyl 2-(benzyloxycarbonylamino)-4-(4-phenyl-1H1,2,3-triazol-1-yl)butanoate ((S)-4d). IR (KBr): 3394, 3135, 3092, 3063, 3031, 2945, 1725, 1713, 1500, 1463, 1455, 1430, 1289, 1274, 1215, 1049. ${ }^{1} \mathrm{H}-\mathrm{NMR}\left(\mathrm{CDCl}_{3}, 300 \mathrm{MHz}\right): 7.81(\mathrm{~d}$, $\left.2 \mathrm{H},{ }^{3} \mathrm{~J}=7.2 \mathrm{~Hz}, \mathrm{H}-\mathrm{C}(\mathrm{Ph})\right), 7.80$ (s, 1H, H-C(5')), 7.44 (d, 2H, $\left.{ }^{3} J=7.2 \mathrm{~Hz}, \mathrm{H}-\mathrm{C}(\mathrm{Ph})\right), 7.42(\mathrm{~m}, 1 \mathrm{H}, \mathrm{H}-\mathrm{C}(\mathrm{Ph})) 7.34(\mathrm{~m}, 10 \mathrm{H}$, $\mathrm{H}-\mathrm{C}(\mathrm{Ph})), 5.53\left(\mathrm{~d}, 1 \mathrm{H},{ }^{3} \mathrm{~J}=8.1 \mathrm{~Hz}, \mathrm{NH}\right), 5.12,5.11(2 \mathrm{~s}, 4 \mathrm{H}$, $\left.\mathrm{O}-\mathrm{CH}_{2}-\mathrm{Ph}\right), 4.46(\mathrm{~m}, 3 \mathrm{H}, \mathrm{H}-\mathrm{C}(2 ; 4)), 2.52-2.35(2 \mathrm{~m}, 2 \mathrm{H}, \mathrm{H}-$ $\mathrm{C}(3)) .{ }^{13} \mathrm{C}-\mathrm{NMR}\left(\mathrm{CDCl}_{3}, 75.5 \mathrm{MHz}\right): 170.9,156.1,147.6$, $135.9,134.7,130.4,128.7,128.6,128.6,128.5,128.4,128.2$, $128.1,128.0,125.6,120.3,67.6,67.2,51.6,46.5,32.9$. 
(S)-Benzyl 2-(benzyloxycarbonylamino)-4-(4-(4methylphenyl)-1H-1,2,3-triazol-1-yl)butanoate ((S)-4e). IR (KBr): $3393,2924,1711,1458,1376,1303,1155,1051 .{ }^{1} \mathrm{H}-$ NMR $\left(\mathrm{CDCl}_{3}, 300 \mathrm{MHz}\right): 7.74$ (s, 1H, H-C(5')), 7.69 (d, 2H, $\left.{ }^{3} J=8.1 \mathrm{~Hz} \mathrm{H}-\mathrm{C}(\mathrm{Ph})\right), 7.35(\mathrm{~m}, 10 \mathrm{H}, \mathrm{H}-\mathrm{C}(\mathrm{Ph})), 7.21(\mathrm{~m}, 2 \mathrm{H}$, $\mathrm{H}-\mathrm{C}(\mathrm{Ph})), 5.51\left(\mathrm{~d}, 1 \mathrm{H},{ }^{3} J=7.4 \mathrm{~Hz}, \mathrm{NH}\right), 5.12,5.11(2 \mathrm{~s}, 4 \mathrm{H}$, $\left.\mathrm{O}-\mathrm{CH}_{2}-\mathrm{Ph}\right), 4.45(\mathrm{~m}, 3 \mathrm{H}, \mathrm{H}-\mathrm{C}(2,4)), 2.57-2.33(2 \mathrm{~m}, 2 \mathrm{H}, \mathrm{H}-$ $\left.\mathrm{C}(3)), 2.38\left(\mathrm{~s}, 3 \mathrm{H}, \mathrm{Ph}-\mathrm{CH}_{3}\right)\right) \cdot{ }^{13} \mathrm{C}-\mathrm{NMR}\left(\mathrm{CDCl}_{3}, 75.5 \mathrm{MHz}\right)$ : $170.5,155.6,147.4,137.6$ (2C), 134.3 (2C), 129.0, 128.3, $128.1,128.0,127.9,127.7,127.2,125.2,119.5,67.3,66.9$, $51.3,46.0,32.8,20.8$.

\section{L-homoalanine $\quad$ - 1,2:5,6-di-O-isopropylidene- $\alpha$-D-} glucofuranose conjugate ((S)-4f). IR (KBr): 3386, 3339, 3143, 3111, 3091, 3066, 3035, 2938, 2988, 2102, 1960, 1881, $1725,1609,1587,1525,1455,1383,1327,1265,1215,1164$, 1122, 1082. ${ }^{1} \mathrm{H}-\mathrm{NMR}\left(\mathrm{CDCl}_{3}, 300 \mathrm{MHz}\right): 7.63(\mathrm{~s}, 1 \mathrm{H}, \mathrm{H}-$ $\left.\mathrm{C}\left(5^{\prime}\right)\right), 7.34(\mathrm{~m}, 10 \mathrm{H}, \mathrm{H}-\mathrm{C}(\mathrm{Ph})), 5.84\left(\mathrm{~d}, 1 \mathrm{H},{ }^{3} \mathrm{~J}=3.6 \mathrm{~Hz}, \mathrm{H}-\right.$ $\left.\mathrm{C}\left(1{ }^{\prime}\right)\right), 5.59\left(\mathrm{~d}, 1 \mathrm{H},{ }^{3} J=7.9 \mathrm{~Hz}, \mathrm{NH}\right), 5.12,5.11(2 \mathrm{~s}, 4 \mathrm{H}, \mathrm{O}-$ $\left.\mathrm{CH}_{2}-\mathrm{Ph}\right), 4.77\left(2 \mathrm{~d}, 2 \mathrm{H}, \mathrm{AB}\right.$ syst, $\left.{ }^{2} J=12.6 \mathrm{~Hz}, \mathrm{H}-\mathrm{C}\left(1^{\prime}{ }^{\prime \prime}\right)\right), 4.59$ $\left(\mathrm{d}, 1 \mathrm{H},{ }^{3} J=3.8 \mathrm{~Hz}, \mathrm{H}-\mathrm{C}\left(2^{\prime \prime}\right)\right), 4.40$ (m, 3H, H-C(2); H-C(4)), 4.31 (m, 1H, H-C(4'), 4.13 - 3.97 (m, 3H, H-C(3"'), H$\mathrm{C}\left(5^{\prime}\right.$ '), H-C(6')), 2.52, 2.30 (2m, 2H, H-C(3)), 1.48 (s, 3H, $\mathrm{CH} 3), 1.41$ (s, 3H, CH3), 1.34 (s, 3H, CH3), 1.29 (s, 3H, CH3). ${ }^{13} \mathrm{C}-\mathrm{NMR}\left(\mathrm{CDCl}_{3}, 75.5 \mathrm{MHz}\right): 170.8,155.8,134.7$, 128.7, 128.6, 128.5, 128.4, 128.4, 128.3, 128.1, 111.8, 109.0, $105.1,82.6,81.7,81.0,73.3,68.4,67.7,67.3,63.9,51.6,46.5$, $33.1,30.9,26.8,26.7,26.6,26.1,25.4$.

(S)-Benzyl 2-(benzyloxycarbonylamino)-4-(4-(1hydroxycyclohexyl)-1H-1,2,3-triazol-1-yl)butanoate ((S)4g). IR (KBr): 3344, 3150, 3089, 3063, 3036, 2927, 2855, $1737,1691,1534,1497,1455,1385,1338,1286,1263,1217$, $1185,1140,1084,1054,1037,1001 .{ }^{1} \mathrm{H}-\mathrm{NMR}\left(\mathrm{CDCl}_{3}, 300\right.$ MHz): $7.35\left(\mathrm{~m}, 11 \mathrm{H}, \mathrm{H}-\mathrm{C}(\mathrm{Ph}), \mathrm{H}-\mathrm{C}\left(5^{\prime}\right)\right), 5.51\left(\mathrm{~d}, 1 \mathrm{H},{ }^{3} \mathrm{~J}=6.8\right.$ $\mathrm{Hz}, \mathrm{NH}), 5.13,5.11$ (2s, 4H, O- $\left.\mathrm{CH}_{2}-\mathrm{Ph}\right), 4.39$ (m, 3H, H-C(2); $\mathrm{H}-\mathrm{C}(4)), 2.52$ (bs, 1H, OH), 2.40-1.16 (m, 12H, H-C(3); Cy). ${ }^{13} \mathrm{C}-\mathrm{NMR}\left(\mathrm{CDCl}_{3}, 75.5 \mathrm{MHz}\right): 170.5,155.6,146.2,135.5$, $134.4,128.3,128.2,128.1,128.0,127.9,127.7,121.1,67.2$, 66.8 (2C), 51.3, 46.2, 37.7, 36.8, 32.5 (2C), 24.9, 21.5.

\section{(S)-Benzyl 2-(benzyloxycarbonylamino)-4-(4-(2-} hydroxypropan-2-yl)-1H-1,2,3-triazol-1-yl)butanoate ((S)4h). IR (KBr): 3332, 3160, 3090, 3068, 3035, 2971, 2931, 1690, 1537, 1497, 1456, 1382, 1284, 1262, 1206, 1175, 1148 , 1087, 1052. ${ }^{1} \mathrm{H}-\mathrm{NMR}\left(\mathrm{CDCl}_{3}, 300 \mathrm{MHz}\right): 7.48$ (bs, $1 \mathrm{H}, \mathrm{H}-$ $\left.\mathrm{C}\left(5^{\prime}\right)\right), 7.35(\mathrm{~m}, 10 \mathrm{H}, \mathrm{H}-\mathrm{C}(\mathrm{Ph})), 5.55\left(\mathrm{~d}, 1 \mathrm{H},{ }^{3} J=7.7 \mathrm{~Hz}, \mathrm{NH}\right)$, 5.13, 5.11 (2s, 4H, O- $\left.\mathrm{CH}_{2}-\mathrm{Ph}\right), 4.38$ (m, 3H, H-C(4); H-C(2)), 2.52, 2.31 (2m, 2H, H-C(3)), 1.62(s, 6H, H-C(1' '); H-C(3')). ${ }^{13} \mathrm{C}-\mathrm{NMR}\left(\mathrm{CDCl}_{3}, 75.5 \mathrm{MHz}\right): 170.9,156.1,147.9,135.9$, $134.8,128.7$ (2C), 128.5, 128.4, 128.3, 128.1 (2C), 67.7, 67.3 (2C), 51.7, 46.5, 33.0, 30.4.

(S)-Benzyl 2-(benzyloxycarbonylamino)-4-(4-hexyl-1H1,2,3-triazol-1-yl)butanoate ((S)-4i). IR (KBr): 3366, 3125, 3069, 3031, 2957, 2927, 1744, 1698, 1514, 1454, 1378, 1351, 1294, 1259, 1239, 1062, 1025. ${ }^{1} \mathrm{H}-\mathrm{NMR}\left(\mathrm{CDCl}_{3}, 300 \mathrm{MHz}\right)$ : $7.35\left(\mathrm{~m}, 11 \mathrm{H}, \mathrm{H}-\mathrm{C}(\mathrm{Ph}), \mathrm{H}-\mathrm{C}\left(5^{\prime}\right)\right), 5.50\left(\mathrm{~d}, 1 \mathrm{H},{ }^{3} J=7.5 \mathrm{~Hz}\right.$, $\mathrm{NH}), 5.12,5.11\left(2 \mathrm{~s}, 4 \mathrm{H}, \mathrm{O}-\mathrm{CH}_{2}-\mathrm{Ph}\right), 4.40(\mathrm{~m}, 2 \mathrm{H}, \mathrm{H}-\mathrm{C}(2))$, 2.68 (m, 2H, H-C(1")), 2.50 (m, 1H, H-C(4)), 2.30 (m, 2H, H-C(3)), 1.65 (m, 2H, H-C(2'))), 1.31 (m, 6H, H-C(3' '); H-
$\mathrm{C}(4$ ') $)$ H-C(5')), 0.88 (t, $\left.3 \mathrm{H},{ }^{3} \mathrm{~J}=6.4 \mathrm{~Hz} \mathrm{H}-\mathrm{C}(6),\right)$. ${ }^{13} \mathrm{C}-$ NMR $\left(\mathrm{CDCl}_{3}, 75.5 \mathrm{MHz}\right): 170.7,156.1,148.1,135.9,134.8$, 128.7, 128.7, 128.6, 128.4, 128.3, 128.1 (2C), 67.7, 67.2, 51.7, $33.2,31.6,29.7,29.3,28.9,25.6,22.5,14.0$.

\section{ACKNOWLEDGEMENTS}

The authors are indebted to Dr. Osvalds Pugovičs (the Latvian Institute of Organic Synthesis) for HPLC analysis on CROWNPAK $^{\circledR} \mathrm{CR}(+)$ column and to Vitālijs Rjabovs for helpful discussions. The authors thank Mārtinšs Otikovs for initial experiments with L-azidohomoalanine ethyl ester. Grindeks JSC is acknowledged for kind donation of organic solvents and Syntagon Baltic Ltd for analytical help.

\section{REFERENCES}

1. Kamal, A., Shankaraiah, N., Devaiah, V., Laxma Reddy, K., Juvekar, A., Sen, S., Kurian, N., Zingde, S. Synthesis of 1,2,3-triazole-linked pyrrolobenzodiazepine conjugates employing 'click' chemistry: DNAbinding affinity and anticancer activity. Bioorganic \& Medicinal Chemistry Letters, 2008, vol. 18, N 4, p. 1468-1473. http://dx.doi.org/10.1016/j.bmcl.2007.12.063

2. Pradere, U., Roy, V., McBrayer, T. R., Schinazi, R. F., Agrofoglio, L. A. Preparation of ribavirin analogues by copper- and ruthenium-catalyzed azide-alkyne 1,3-dipolar cycloaddition. Tetrahedron, 2008, vol 64, N 38, p. 9044-9051. http://dx.doi.org/10.1016/j.tet.2008.07.007

3. Montagu, A., Roy, V., Balzarini, J., Snoeck, R., Andrei, G., Agrofoglio, L. A. Synthesis of new C5-(1-substituted-1,2,3-triazol-4 or 5-yl)-2'-deoxyuridines and their antiviral evaluation. European Journal of Medicinal Chemistry, 2011, vol 46, N 2, p. 778-786. http://dx.doi.org/10.1016/j.ejmech.2010.12.017

4. Ferreira, S. B., Sodero, A. C. R., Cardoso, M. F. C., Lima, E. S., Kaiser, C. R., Silva Jr., F. P., Ferreira, V. F. Synthesis, biological activity, and molecular modeling studies of $1 H$-1,2,3-triazole derivatives of carbohydrates as $\alpha$-glucosidases inhibitors. Journal of Medicinal Chemistry, 2010, vol. 53, p. 2364-2375. http://dx.doi.org/10.1021/jm901265h

5. Rjabova, J., Rjabovs, V., Moreno Vargas, A. J., Moreno Clavijo, E., Turks, M. Synthesis of novel 3-deoxy-3-C-triazolylmethylallose derivatives and evaluation of their biological activity. Central European Journal of Chemistry, 2012, vol. 10, N 2, 386-394. http://dx.doi.org/10.2478/s11532-012-0002-9

6. Tornøe, C. W., Christensen, C., Meldal, M. Peptidotriazoles on solid phase: [1,2,3]-triazoles by regiospecific copper(I)-catalyzed 1,3-dipolar cycloadditions of terminal alkynes to azides. Journal of Organic Chemistry, 2002, vol. 67, N 9, p. 3057-3064. http://dx.doi.org/10.1021/jo011148j

7. Rostovtsev, V. V., Green, L. G., Fokin, V. V., Sharpless, K. B. A stepwise Huisgen cycloaddition process: copper(I)-catalyzed regioselective "ligation" of azides and terminal alkynes. Angewandte Chemie International Edition, 2002, vol. 41, N 14, p. 2596-2599. http://dx.doi.org/10.1002/1521-3773(20020715)41:14<2596::AIDANIE2596>3.0.CO;2-4

8. Mindt, T.-L., Struthers, H., Brans, L., Anguelov, T., Schweinsberg, C., Maes, V., Tourwé, D., Schibli, R. "Click to chelate": Synthesis and installation of metal chelates into biomolecules in a single step. Journal of the American Chemical Society, 2006, vol. 128, N 47, p. 15096-15097. http://dx.doi.org/10.1021/ja066779f

9. Li, C., Tang, J., Xie. J. Synthesis of crosslinking amino acids by click chemistry. Tetrahedron, 2009, vol. 65, N 38, p. 7935-7941. http://dx.doi.org/10.1016/j.tet.2009.07.054

10. Sai Sudhir, S., Phani Kumar, N. Y., Chandrasekaran, S. Click chemistry inspired synthesis of ferrocene amino acids and other derivatives. Tetrahedron, 2010,vol. 66, N 6, p. 1327-1334. http://dx.doi.org/10.1016/j.tet.2009.12.011

11. Kuijpers, H.-M., Groothuys, S., Keereweer, A.-R., Quaedflieg, L.-M., Blaauw, R.-H., Delft, F.-L., Rutjes. J.-T. Expedient synthesis of triazole-linked glycosyl amino acids and peptides. Organic Letters, 2004, vol. 6, N 18, p. 3123-3126. http://dx.doi.org/10.1021/o1048841o 
12. Dondoni, A., Giovannini, P.-P., Massi, A. Assembling heterocycletethered $C$-glycosyl and $\alpha$-amino acid residues via 1,3-dipolar cycloaddition reactions. Organic Letters, 2004, vol. 6, N 17, p. 29292932. http://dx.doi.org/10.1021/o1048963g

13. Nagarajan, S., Taskent-Sezgin, H., Parul, D., Carrico, I., Raleigh, D. P., Dyer, R. B. Differential ordering of the protein backbone and side chains during protein folding revealed by site-specific recombinant infrared probes. Journal of the American Chemical Society, 2011, vol. 133, N 50, p. 20335-20340. http://dx.doi.org/10.1021/ja2071362

14. Taskent-Sezgin, H., Chung, J., Banerjee, P. S., Nagarajan, S., Dyer, R. B., Carrico, I., Raleigh, D. P. Azidohomoalanine: a conformationally sensitive IR probe of protein folding, protein structure, and electrostatics. Angewandte Chemie International Edition, 2010, vol. 49, N 41, 7473 7475. http://dx.doi.org/10.1002/anie.201003325

15. Hang, H. C., Wilson, J. P., Charron, G. Bioorthogonal chemical reporters for analyzing protein lipidation and lipid trafficking. Accounts of Chemical Research, 2011, vol. 44, N 9, p. 699-708. http://dx.doi.org/10.1021/ar200063v

16. Sletten, E. M., Bertozzi, C. R. From mechanism to mouse: a tale of two bioorthogonal reactions. Accounts of Chemical Research, 2011, vol. 44, N 9, 666-676. http://dx.doi.org/10.1021/ar200148z

17. Ostrovskis, P., Volla, C. M. R., Turks, M., Marković, D. Application of metal free click chemistry in biological studies. Current Organic $\begin{array}{lllll}\text { Chemistry, 2013, vol 17, p } & \text { 610-640 }\end{array}$ http://dx.doi.org/10.2174/1385272811317060006

18. Johansson, H., Pedersen, D. S. Azide- and alkyne-derivatised a-amino acids. European Journal of Organic Chemistry, 2012, N 23, p. $4267-$ 4281. http://dx.doi.org/10.1002/ejoc.201200496

19. Stanley, N. J., Pedersen, D. S., Nielsen, B., Kvist, T., Mathiesen, J. M., Bräuner-Osborne, H., Taylor, D. K., Abell, A. D. 1,2,3-Triazolyl amino acids as AMPA receptor ligands. Bioorganic \& Medicinal Chemistry Letters, 2010, vol. 20, N 24, p. 7512-7515. http://dx.doi.org/10.1016/j.bmcl.2010.09.139

20. Gajewski, M., Seaver, B., Esslinger, C.-S. Design, synthesis, and biological activity of novel triazole amino acids used to probe binding interactions between ligand and neutral amino acid transport protein SN1. Bioorganic \& Medicinal Chemistry Letters, 2007, vol. 17, N 15, p. 4163 4166. http://dx.doi.org/10.1016/j.bmcl.2007.05.061

21. Strelninikova, N. Synthesis of novel triazole substituted amino acids : Bachelor Thesis. Riga Technical University. Riga, 2010. 67 pp.

22. Streḷnikova N., Otikovs M., Kumpiṇš V., Kalējs U., Turks M. Synthesis of Enantiopure Triazole-Modified Homoalanine Derivatives. In: International Conference on Organic Synthesis BOS2010, Riga, Latvia, June 27-30, 2010. Abstracts. Riga, 2010, p 194-194.

23. Roth, S., Drewe, W. C., Thomas, N. R. A concise and scalable route to L-azidohomoalanine. Nature Protocols, 2010, vol. 5, p. 1967-1973. http://dx.doi.org/10.1038/nprot.2010.164

24. Kim, S., Lee, J. I., Kim, Y. C. A simple and mild esterification method for carboxylic acids using mixed carboxylic-carbonic anhydrides. Journal of Organic Chemistry, 1985, vol. 50, N 5, p. 560-565. http://dx.doi.org/10.1021/jo00205a004

25. Turks, M., Rijkure, I., Belyakov, S., Zicāne, D., Kumpiṇš, V., Bizdēna, $\overline{\mathbf{E}}$., Meikas, A., Valkna, A. On differences between racemic and enantiomerically pure forms of aziridine-2-carboxamide. Chemistry of Heterocyclic Compounds, 2012, vol 48, N 6, p. 861-868. http://dx.doi.org/10.1007/s10593-012-1067-2

26. Gawley, R. E. Do the terms "\% ee" and "\% de" make sense as expressions of stereoisomer composition or stereoselectivity? Journal of Organic Chemistry, 2006, vol. 71, N 6, p. 2411-2416. http://dx.doi.org/10.1021/jo052554w

Māris Turks obtained his B.Sc. in Chemistry from the University of Latvia in 1998 and M.Sc. from Riga Technical University in 2000. Further, he was a doctoral student at the Swiss Federal Institute of Technology, Lausanne under the guidance of Professor Pierre Vogel, where he earned his Dr.ès.sc. degree in Synthetic Organic Chemistry in 2005.

M.Turks has worked as a Postdoctoral Associate at the Swiss Federal Institute of Technology, Lausanne in 2005 followed by appointment as SNSF Postdoctoral Fellow at Stanford University under the guidance of Professor Barry M.Trost in 2006. In 2007 he accepted an academic position at the Faculty of Materials Science and Applied Chemistry, Riga Technical University, where currently he is a Professor and the Head of the Institute of Technology of Organic Chemistry. Dr. Turks' current research interests deal with carbohydrate chemistry, functionalized heterocycles, and applications of liquid sulfur dioxide in organic synthesis.

Contact data: 14/24 Azenes Str., Riga, LV-1007, Latvia

E-mail: maris_turks@ktf.rtu.lv

Nataljja Streḷnikova obtained her B.Sc. (2010) and M.Sc. (2012) degrees in Chemical Technology from Riga Technical University. She worked as a Research Assistant at the Institute of Technology of Organic Chemistry until June 2012. Now Natalja Strelnikova is pursuing her PhD studies at the University of Basel, Switzerland.

Viktors Kumpiṇš obtained his Dipl.-Ing. degree in 1985. He has held diverse positions as a Chemist at several academic, industrial, and governmental institutions. Since 2010 Viktors Kumpiñš has been working as a Researcher at the Institute of Technology of Organic Chemistry, Riga Technical University.

Udo Kalējs obtained his degree of Candidate of Chemical Sciences (equals Dr.chem.) in 1982. Until 1989 he was the Head of the Peptide Synthesis Laboratory at company BIOLAR. Since 1989, Udo Kalējs runs a privately held company $B A P E K S$ Ltd and serves in it as the Chairman of the Board. His research interests are mainly related to the fields of polyamine and amino acid chemistry.

Contact data: 14/24 Azenes Str., Riga, LV-1007, Latvia

E-mail: bapeks.u.k@apollo.lv

\section{Māris Turks, Nataḷja Strẹ̦nikova, Viktors Kumpiṇš, Udo Kalējs. Enantiomēri bagātinātu homoalanīnu 1,2,3-triazolilatvasinājumu sintēze}

Dabasvielu, to skaitā aminoskābju, konjugāti ar triazoliem ieguvuši īpašu uzmanību pēdējā desmitgadē, kopš klik ķīmijas koncepta attīstības. Komerciāli pieejamie L- un D-azidohomoalanīna (4-azido-2-amino-butānskābes) atvasinājumi viegli stājas vara(I) katalizētās azīdu alkīnu dipolārajās cikopievienošanās reakcijās ar dažādiem terminālajiem alkīniem. Pie C(4)-aizvietoti 1H-1,2,3-triazol-1-il-homoalanīni iegūstami gan no neaizsargātiem enantiomēri tīriem homoalanīniem, piemēram, no attiecīgā hidrohlorīda, gan no $N$ - un $O$-aizsargātām izejvielām. Šajā kontekstā darbā lietoti $N$-Cbz-O-Bn-L-homoalanīns un $N$-Boc-D-homoalanīna dicikloheksilamonija sāls. 1,2,3-Triazolu konjugātu sintēze tolerē dažādas funkcionālās grupas: iegūti cikloadukti no 5-heksīnnitrila, 3-butīn-1-ola, 4-pentīn-1-ola, fenilacetilēna, tolilacetilēna, 3-O-propagil1,2:5,6-di- $O$-izopropilidēn- $\alpha$-D-glikofuranozes, 1-etinil-1-cikloheksanola, 2-metil-3-butīn-2-ola un 1-oktīna. $N$ - un $O$-aizsarggrupu lietošana atvieglo starpproduktu attīrǐšanu, kurai var lietot silikagēla kolonnu hromatogrāfiju. Šādi attīrītus triazola ciklu saturošus starpproduktus iespējams katalītiski hidrogenēt, tādējādi iegūstot praktiski tīrus galaproduktus, jo aizsarggrupu nošķkelšanas blakusprodukti ir toluols un $\mathrm{CO}_{2}$. $\mathrm{N}$-Cbz-O-Bn-L-homoalanīna gadījumā triazolu sintēzē sasniegti iznākumi līdz 84\% un aizsargrupu nošķelšanā līdz 70\%. Arī 1H-1,2,3-triazol1-il-homoalan̄ini, kas iegūti no $N$-Boc-D-homoalanīna dicikloheksilamīnija sāls, ir attīrāmi ar tiešās fāzes hromatogrāfijas palīdzību. Pēc citas pieejas iespējams lietot neaizsargātu aminoskābi tās hidrohlorīda veidā. Šī metode, būdama īsāka no sintētiskā viedokḷa, raksturojama ar darbietilpīgu attīrǐšanu - puspreparatīvo AEŠH. Citas aminoskābju ķīmijā raksturīgās attīrīšanas metodes - jonapmaiņas hromatogrāfija un manuālā kolonnu hromatogrāfija uz C18 apgrieztās fāzes - nedeva vēlamos rezultātus. Parādīts, ka pie C(4)-aizvietotu 1H-1,2,3-triazol-1-ilhomoalanīnu enantiomēru attiecības tiešai AEŠH analīzei pielietojama $\operatorname{CROWNPAK}^{\circledR} \mathrm{CR}(+)$ stacionārā fāze, kas veidota no hirāla krauna ētera selektora. Iegūtajiem hirālajiem L- un D-homoalanīna triazolu konjugātiem noteikts to enantiomērais pārākums, kas svārstījās no $95 \%$ līdz $>99.5 \%$. Produkti ar augstu enantiomēro tīrību iegūti sintēzēs, kas veiktas $20-25{ }^{\circ} \mathrm{C}$ temperatūrā katalītiskās sistēmas $\mathrm{CuSO}_{4} /$ nātrija askorbāts klātienē. Reakcijas maisījuma sildīšana līdz $70{ }^{\circ} \mathrm{C}$ vara(I) katalizatora un trešějo amīnu klātienē inducē dal̦ēju produktu racemizāciju līdz $95 \%$ ee. 
Марис Туркс, Наталья Стрельникова, Викторс Кумпиньш, Удо Калейс. Синтез энантиомерно обогащенных производных 1,2,3-триазолилгомоаланина

Конъюгаты природных веществ, в том числе аминокислот, и триазолов получили особое внимание в прошедшее десятилетие после открытия концепции клик-химии. Коммерчески доступные производные D- и L-азидогомоаланина (4-азидо-2-аминобутановая кислота) реагируют с различными терминальными алкинами в катализируемых медью(I) реакциях 1,3-диполярного циклоприсоединения. Замещенные $1 H-1,2,3-$ триазол-1-ил-гомоаланины получают как из энантиомерно чистых гомоаланинов, к примеру, из соответствующего гидрохлорида, так и из $N$ - и $O$-защищенных исходных веществ. В данной работе использованы $N$-Cbz$O$-Вn-L-гомоаланин и дициклогексиламмониевая соль $N$-Вос-D-гомоаланина. Синтез 1,2,3-триазолов позволяет использовать различные функциональные группы, благодаря чему получены аддукты 5-гексиннитрила, 3-бутин-1-ола, 4-пентин-1-ола, фенилацетилена, п-толилацетилена, 3-O-пропаргил-1,2:5,6-ди-O-изопропилиден- $\alpha$-D-глюкофуранозы, 1 -этинил-1-циклогексанола, и 1-октина. Использование $N$ - и $O$-защитных групп облегчает процесс очистки промежуточных продуктов, для которого можно использовать колонную хроматографию на силикагеле. Очищенные таким образом триазолы можно каталитически гидрогенировать с целью получения практически чистых продуктов, ведь в результате снятия защитных групп выделяются толуол и углекислый газ. В синтезах продуктов циклоприсоединения $N$ - Cbz- $O$-Bn-L-гомоаланина выходы достигали $84 \%$, а в реакциях снятия защитных групп $70 \%$. Продукты, полученные из дициклогексиламмониевой соли $N$-Вос-D-гомоаланина, также могут быть очищены при помощи колонной хроматографии на прямой фазе. Другой подход необходим при использовании гидрохлорида гомоаланина. В таком случае, при меньшей синтетической работе, для очистки используется работоемкая полупрепаративная высокоэффективная жидкостная хроматография. Другие методы очистки аминокислот - ионобменная хроматография и колонная хроматография на обратной фазе не дали желаемого результата. Показано, что для анализа энантиомерного состава при С(4)-замещенных 1H-1,2,3-триазол-1-илгомоаланинов может быть использована хиральная стационарная фаза $\mathrm{CROWNPAK}^{\circledR} \mathrm{CR}(+)$, состоящая из хирального краун-эфира. Для полученных хиральных конъюгатов D- и L-гомоаланинов определен избыток энантиомера, который колебался от $95 \%$ до $99,5 \%$. Продукты с высокой энантиомерной чистотой получены в реакциях при $20-25{ }^{\circ} \mathrm{C}$ с использованием каталитической системы $\mathrm{CuSO}_{4} /$ аскорбат натрия. Нагревание реакционной смеси до $70{ }^{\circ} \mathrm{C}$ в присутствии меди(I) и третичных аминов приводит к частичной рацемизации продукта до $95 \%$ э.и. 